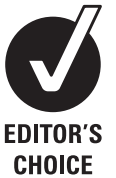

CHOICE
${ }^{1}$ Department of Public Health, University of Birmingham, Birmingham, UK

${ }^{2}$ NICE, London, UK

${ }^{3}$ Department of Psychiatry,

Kings College, London, UK

Correspondence to

Professor Peter Littlejohns, NICE, Midicity Place, 71 High Holborn, London SW4 9HF, UK; peter.littlejohns@nice.org.uk

Received 28 July 2011 Revised 25 November 2011 Accepted 28 November 2011 Published Online First

2 January 2012

PAPER

\title{
National Institute for Health and Clinical Excellence appraisal and ageism
}

\author{
Andrew Stevens, ${ }^{1}$ Nick Doyle, ${ }^{2}$ Peter Littlejohns, ${ }^{2}$ Mary Docherty ${ }^{3}$
}

\begin{abstract}
The requirements of the UK Equality Act 2010 and some high profile criticism for using a potentially ageist methodology have prompted the National Institute for Health and Clinical Excellence (NICE) to assess the processes and methodology it uses to make appraisal decisions. This paper argues that NICE has established rigorous systems to protect against ageist decisions, has no track record of ageism and is well placed to meet the requirements of new UK equality legislation.
\end{abstract}

The National Institute for Health and Clinical Excellence (NICE) is an independent organisation that provides guidance and sets quality standards to improve people's health and prevent and treat ill health in the UK. One of its key activities is undertaken through its health technology programme, which makes recommendations on the use of new and existing medicines and treatments within the NHS, such as: medicines and surgical procedures (such as repairing hernias).

NICE health technology appraisals have a high political profile and are often beset with controversy. A fundamental debate continues over the Institute's approach to incremental cost-effectiveness analysis, particularly the use of cost per quality-adjusted life-year (OALY). Some argue that this places an emphasis on health service efficiency that may not be in touch with societal values. The Institute argues, however, that it expects its advisory committees when deciding to recommend interventions that their decisions should not be based on evidence of their relative costs and benefits alone, but that they must consider other factors when developing its guidance, including the need to distribute health resources in the fairest way within society as a whole. ${ }^{1-4}$ However, the debate continues and is most vocal in the context of age discrimination. This paper addresses the ageist charge specifically, but the principles invoked in responding can also be applied to other characteristics that critics suggest could lead to discrimination.

The Institute believes that the ageist arguments fall short on three counts: (1) they have not examined how the OALY has been applied within cost-effectiveness calculations, and the underlying improbability of an ageist decision; (2) they fail to account for systems and processes in place within NICE that further safeguard against any possible ageist outcomes; and (3) they have not reviewed NICE's actual decision history.

This paper explores the theoretical argument that NICE's methods are ageist, describes the safeguards against ageism, and reviews NICE's actual track record of decisions.

\section{THE THEORETICAL AGEISM ARGUMENT AND NICE'S TECHNICAL RESPONSE}

The theoretical argument is predicated on the fact that the calculation of incremental cost effectiveness underpins NICE's appraisal decision making. ${ }^{5}$ This is true, but it misses both the improbability of an ageist calculation and the discretion of the appraisal committees to consider other factors, particularly discrimination, too. The boundaries of this discretion are laid out in the social value judgements document discussed below.

NICE assesses the value of a new intervention by taking into account not only how effective a new treatment is but how much it costs. This is achieved by deriving the incremental cost-effectiveness ratio (ICER). This is calculated by dividing the difference between the cost of the new treatment and the cost of the comparator treatment (ie, the normal treatment currently available to patients), by the difference in the benefits that they offer to patients. These benefits are expressed as OALY. OALY combine a calculation of length of life with quality of life. ${ }^{6}$

\section{$\frac{\text { Cost } A-\text { Cost B }}{\text { Benefit } A-\text { Benefit B }}$}

The ICER is expressed as a cost per OALY. NICE's advisory committee considers the ICER in the context of the threshold range that the Institute is advised represents what the health service in the UK, in practice the NHS, can afford, ie, the level of the cost per OALY that would ensure that any new intervention did not displace more health than it added. The value that the Institute uses is a range of $£ 20000-30000$ per OALY. The Institute has commissioned through the Medical Research Council and National Institute for Health Research a programme of research to test the validity of these values. ${ }^{7}$ However, advisory committees are expected to use judgement in applying the threshold. Above a most plausible ICER of $£ 20000$ per OALY gained, judgements about the acceptability of the intervention as an effective use of NHS resources should specifically take account of the following factors:

1. The degree of certainty around the ICER. In particular, advisory bodies will be more cautious about recommending a technology when they are less certain about the ICER presented in the cost-effectiveness analysis.

2. The presence of strong reasons indicating that the assessment of the change in the quality of 
life is inadequately captured, and may therefore misrepresent the health gain.

3. When the intervention is an innovation that adds demonstrable and distinct substantial benefits that may not have been adequately captured in the measurement of health gain. As the ICER of an intervention increases in the $£ 20$ 000-30000 range, an advisory body's judgement about its acceptability as an effective use of NHS resources should make explicit reference to the relevant factors considered above. Above a most plausible ICER of $£ 30000$ per OALY gained, advisory bodies will need to make an increasingly strong case for supporting the intervention as an effective use of NHS resources with respect to the factors considered above.

The variation of the anticipated gain in length of life between people of different ages means that there are greater theoretical gains for a younger person in receipt of a life-saving treatment than for an elderly person. While a 20 year old can expect longevity of approximately a further 55 years, a 45 year old would have longevity of 35 years, and a 70 year old a longevity of 15 years. Saving the life of a 20 year old, therefore, achieves greater OALY gains than saving the life of a 70 year old. However, this theoretical possibility that the OALY is inherently ageist does not stand up when the actual OALY calculations NICE makes are more closely considered.

Table 1 shows what the purely cost-effectiveness-based decisions would be for treatments generating a year of life gain and for life saving treatments for a 20 year old, a 45 year old and a 70 year old at different costs. It illustrates a point argued by Paulden and Culyer's ${ }^{8}$ economic modelling of NICE's decision making that ageist discrimination as a result of the application of OALY could only occur if the technology in question fits very specific conditions: the ratio of costs to QALY must be lower over the long term than over the short term; the ICER for patients with shorter life expectancy must lie above the costeffectiveness threshold; and the ICER for patients with longer life expectancy must fall below the cost-effectiveness threshold.

Lines 1-3 of table 1 show that for the 1 year gain decisions, age discrimination cannot apply because the longevity head- room is, by definition, identical for all age groups. The clinical evidence for life extension of a few months to a few years could, of course, show a differential advantage for different age groups, but in practice there are relatively few age-stratified trial results, and it is NICE's practice to assume that what applies to one age group within a particular appraisal will apply inter alia to others.

A more potentially problematical situation arises when normal life expectancy is gained over potential imminent death. Lines 4-6 of table 1 show that when normal life expectancy is attained for $£ 450000, £ 700000$ and a million pounds, the ICER vary between a 45 year old and a 70 year old, but the decisions do not discriminate except in the one million pound category. Although life expectancy gained for $£ 700000$ yields an ICER above NICE's normal $\$ 30000$ per OALY upper limit in the case of a 70 year old, in fact the resumption of normal life expectancy, when there would otherwise be early death, is covered by NICE's extended end-of-life rules (see below) and an ICER of $£ 47000$ is still acceptable.

So what happens when there is a million pound treatment that is curative in the elderly? NICE has never faced this situation but it is highly unlikely that a knee-jerk OALY-based decision would be made. This hypothetical situation is of questionable significance, not only because of its rarity (it has not yet occurred), but also because NICE appraisal committees are not obliged to accept blindly the outcome of this selective part of its methodology guidance. Indeed, NICE's track record to date of assuming an identical (trial-based or averaged) benefit across all age groups reflects the fact that it is incumbent on them to consider the possibility of ageism. The appraisal committees can go further than standardising OALY gain assumptions across age groups. They retain authority to exercise discretion up to the point at which to do so would be perverse.

\section{NICE'S PROCEDURAL PROTECTIONS AGAINST AGEIST DECISIONS}

Arguments claiming that NICE must be ageist because it uses QALY have also not considered the context in which OALY are applied: NICE has implemented processes, built around

Table 1 Aging and the Quality Adjusted Life Year (OALY): the theoretical problem

\begin{tabular}{lllllll}
\hline & ICER & & & & \\
\cline { 2 - 4 } & 20 Years & 45 Years & 70 Years & & Decision & Explanation \\
\hline 1 Year life gain for $£ 30000$ & $£ 30000$ & $£ 30000$ & $£ 30000$ & Yes to all & Within $£ 30000$ threshold* \\
1 Year life gain for $£ 45000$ & $£ 45000$ & $£ 45000$ & $£ 45000$ & No to all & Outside $£ 30000$ threshold \\
1 Year life gain at end of life for $£ 45000$ & $£ 45000$ & $£ 45000$ & $£ 45000$ & Yes to all & Within de facto EOL rules threshold $\dagger$ \\
Normal life expectancy gain for $£ 450000$ & $£ 8000$ & $£ 13000$ & $£ 30000$ & Yes to all & Within $£ 30000$ threshold* \\
Normal life expectancy gain at end of life for $£ 700000$ & $£ 13000$ & $£ 20000$ & $£ 47000$ & Yes to all & Within de facto EOL rules threshold $\dagger$ \\
Normal life expectancy gain for $£ 1$ million & $£ 18000$ & $£ 28000$ & $£ 67000$ & Yes only to under 50s? $\ddagger$ & \\
\hline
\end{tabular}

\footnotetext{
An explanation of end-of-life (EOL) supplementary advice as presented in National Institute for Health and Clinical Excellence (NICE) documentation.

EOL stands for end of life. It refers to supplementary advice issued by NICE to the appraisal committees, to be taken into account when appraising treatments that may be life-extending for patients with a short life expectancy, and that are licensed for indications affecting small numbers of patients with incurable illnesses. The additional advice will apply when such treatments have an incremental cost-effectiveness ratio (ICER) in excess of the upper end of the range normally approved by the appraisal committees, using the most plausible ICER agreed by the committee generated by the 'reference case' outlined in the Institute's guide to the methods of technology appraisal, and that may offer demonstrable survival benefits over current NHS practice. The current appraisal methodology recognises that there will be circumstances in which it may be appropriate to recommend the use of treatments with high reference case ICER. The appraisal committee has, in the past, made recommendations above the normal threshold range when it has explicitly identified additional benefits not readily captured in the reference case. This has occurred when the treatment involved has been life extending, licensed or otherwise indicated for small populations with incurable illnesses. This formalises the position of EOL and the supplementary advice should be applied in the following circumstances and when all the criteria referred to below are satisfied:

The treatment is indicated for patients with a short life expectancy, normally less than 24 months and there is sufficient evidence to indicate that the treatment offers an extension to life, normally of at least an additional 3 months, compared with current NHS treatment, and the treatment is licensed or otherwise indicated for small patient populations. When the conditions described are met, the appraisal committee will consider the impact of giving greater weight to quality-adjusted life-years (OALY) achieved in the later stages of terminal diseases, using the assumption that the extended survival period is experienced at the full quality of life anticipated for a healthy individual of the same age, and the magnitude of the additional weight that would need to be assigned to the QALY benefits in this patient group for the cost effectiveness of the technology to fall within the current threshold range. In addition, the appraisal committees will need to be satisfied that the estimates of the extension to life are robust and can be shown or reasonably inferred from either progression-free survival or overall survival (taking account of trials in which crossover has occurred and been accounted for in the effectiveness review), and the assumptions used in the reference case economic modelling are plausible, objective and robust. *NICE methods guide states the threshold should be $£ 20000-30000$. In practice the exceptional circumstances allowing the upper end of the scale prevail.

†The EOL rules allow for the greater valuation of life years in terminal ( $<2$ years to live) illness. The de-facto valuation has been 1.67 , ie, an implied threshold change to $£ 50000$ per $0 A L Y$. $\ddagger$ A circumstance yet to arise. See text.
} 
principles of transparency and stakeholder involvement, to safeguard against ageist decisions. ${ }^{9}$ These include its equality and social value programmes, and recent additions to rules regarding end-of-life treatments. They ensure that all stages of the appraisal process are open and visible and the evidence and reasons behind recommendations accessible, that there is systematic examination of implications for equality, and that public and patient input is actively sought.

\section{Citizens Council and social value principles}

All NICE decisions are informed by eight social value principles formulated with the advice of its lay advisory body, the Citizens Council, the experiences of its guidance advisory bodies and input from ethicists (box 1). The document 'Social values judgements' forms the basis of NICE advice to its advisory bodies on how to apply social value judgements when making decisions. ${ }^{10}$ Both the process and outcomes of appraisals are thus reflective of and receptive to contemporary values and ethical principles held by society. These include an obligation actively to consider health inequalities, such as those associated with age, and an explicit commitment to ensure interventions are only restricted to particular subgroups (eg, determined by age) when there is clear evidence about the increased effectiveness of the intervention in this context. ${ }^{11} 12$

\section{Legal framework}

NICE reinforced the relevant social value principles (7 and 8) with an equality scheme in 2007, which fitted well with the UK Equality Act 2010, which added age as a protected (from discrimination) characteristic. Its equality scheme for the period 2010-13 describes a process that enables it critically to assess the equality impact of its evaluation processes and decisions at key stages in the production of guidance and other products. ${ }^{13} 14$

The review in 2009 of age discrimination in health and social care instigated by the Department of Health in preparation for the ban looked at whether the use of cost-effectiveness measures such as QALY was fair to all age groups. The report of the review recognised that, although some people could be treated less favourably as a result of using OALY (essentially the theoretical scenarion in line 6 of table 1), there were no alternatives that would be practical and less discriminatory in allocating resources. ${ }^{15}$ It supported the continuing use of OALY but wanted specific attention paid to situations in which such use could result in less favourable treatment. It recommended that the Department of Health and the NHS should review the use they made of QALY and other similar support tools, and also the use of age-based criteria. NICE is acting on these recommendations by assuring itself that procedures based on its equality scheme and social value principles uphold its moral and legal

\section{Box 1 The social value principles}

\section{Principle 1}

NICE should not recommend an intervention (ie, a treatment, procedure, action or programme) if there is no evidence, or not enough evidence, on which to make a clear decision.

\section{Principle 2}

Those developing clinical guidelines, technology appraisals, or public health guidance must take into account the relative costs and benefits of interventions (their cost effectiveness) when deciding whether or not to recommend them.

\section{Principle 3}

Decisions about whether to recommend interventions should not be based on evidence of their relative costs and benefits alone. NICE must consider other factors when developing its guidance, including the need to distribute health resources in the fairest way within society as a whole.

\section{Principle 4}

NICE should explain its reasons when it decides that an intervention with an ICER below $£ 20000$ per QALY gained is not cost effective; and when an intervention with an ICER of more than $£ 20000-30000$ per QALY gained is cost effective.

\section{Principle 5}

Although NICE accepts that individual NHS users will expect to receive treatments to which their condition will respond, this should not impose a requirement on NICE's advisory bodies to recommend interventions that are not effective, or are not cost effective enough to provide the best value to users of the NHS as a whole.

\section{Principle 6}

NICE should consider and respond to comments it receives about its draft guidance, and make changes when appropriate. NICE and its advisory bodies must use their own judgement to ensure that what it recommends is cost effective and takes account of the need to distribute health resources in the fairest way within society as a whole.

\section{Principle 7}

NICE can recommend that the use of an intervention is restricted to a particular group of people within the population (eg, people under or over a certain age, or for women only), but only in certain circumstances. There must be clear evidence about the increased effectiveness of the intervention in this subgroup, or other reasons relating to fairness for society as a whole, or a legal requirement to act in this way.

\section{Principle 8}

When choosing guidance topics, developing guidance and supporting those who put its guidance into practice, (NICE) should actively consider reducing health inequalities, such as those associated with sex, age, race, disability and socioeconomic status. 
obligations to ensure decisions do not result in unlawful discrimination and, when possible, advance age equality. ${ }^{16}$

\section{End-of-life appraisal rules}

In response to the apparently increasing public concern that the value placed on the last period of life (when life expectancy was known to be short) was not fully captured by the routine OALY methodology NICE developed additional 'end-of-life rules' ${ }^{17}$ These constitute supplementary advice to the appraisal committee when it appraises treatments that may be life extending for patients with short life expectancy, and which are licensed for indications affecting small numbers of patients with incurable illnesses. ${ }^{18}$ The advice is to be considered when such treatments have an ICER in excess of the upper end of the range normally approved by the appraisal committee. It actively discriminates in favour of people with terminal illness by valuing their last few months of life much more highly than any others. This idea reflects some evidence that society would not necessarily assign the same value to quality of life and life expectancy (measured as QALY) under all circumstances. ${ }^{19}$

NICE has commissioned further research to try and clarify further which circumstances would affect these measures of 'value' and how they can be compared. Input from the Citizens Council for example, suggested that severe illness, childhood

Table 2 NICE decisions and age

\begin{tabular}{|c|c|c|c|}
\hline Year & Appraisal & Decision & Age restriction \\
\hline \multirow[t]{4}{*}{2010} & Rheumatoid arthritis - certolizumab & Yes & No \\
\hline & Soft tissue sarcoma-trabectedin & Yes & No \\
\hline & Hearing impairment cochlear implants & Yes-unilateral & No \\
\hline & & Yes-bilateral & Children and adults with further disability \\
\hline \multirow[t]{17}{*}{2009} & Abdominal aortic aneurysm-endovascular stent grafts & Yes-unruptured & No \\
\hline & Influenza-zanamivir, amantadine and oseltamivir (review) & Yes-at risk & Relaxed at risk criteria $>65$ years \\
\hline & Renal cell carcinoma-sunitinib & Yes & No \\
\hline & Venous thromboembolism-rivaroxaban & Yes & No \\
\hline & Head and neck cancer (squamous cell cancer)—cetuximab & No & NA \\
\hline & Multiple myeloma-lenalidomide & Yes & No \\
\hline & Hepatitis B-tenofovir disoproxil fumarate & Yes & No \\
\hline & Leukaemia (chronic lymphocytic, first line)-rituximab & Yes & No \\
\hline & Colorectal cancer (first line)—cetuximab & Yes if operable & No \\
\hline & Eczema (chronic)-alitretinoin & Yes if severe & No \\
\hline & Renal cell carcinoma-bevacizumab, sorafenib and temsirolimus & No & NA \\
\hline & Gastrointestinal stromal tumours-sunitinib & Yes & No \\
\hline & Lung cancer (non-small cell, first line treatment)—-pemetrexed & Yes & No \\
\hline & Psoriasis-ustekinumab & Yes if severe & No \\
\hline & Acute coronary syndrome-prasugrel & No except emergencies and DM & NA \\
\hline & Cervical cancer (recurrent)-tapotecan & No except patient naive & NA \\
\hline & Lung cancer (small cell)-tapotecan & $\begin{array}{l}\text { Yes if CAV (cyclophosphamide, doxorubicin } \\
\text { and vincristine) contraindicated }\end{array}$ & No \\
\hline \multirow[t]{27}{*}{2008} & Mesothelioma-pemtrexed disodium & Yes (if WHO performance status 0 or 1 ) & No \\
\hline & Psoriasis-infliximab & Yes if severe & No \\
\hline & Lymphoma (follicular non-Hodgkin's)—rituximab & Yes & No \\
\hline & Structural imaging in first episode psychosis & No & NA \\
\hline & Asthma (in adults) corticosteroids & Yes & $>12$ years \\
\hline & Sleep apnoea-continuous positive airway pressure & Yes if moderate or worse & No \\
\hline & Rheumatoid arthritis (refractory)—abatacept & No & NA \\
\hline & Ulcerative colitis (subacute manifestations)-infliximab & No & NA \\
\hline & $\begin{array}{l}\text { Anaemia (cancer treatment induced)-erythropoietin } \\
\text { (alpha and beta) and darbepoetin }\end{array}$ & $\begin{array}{l}\text { No except non-transfusable and some cases } \\
\text { of ovarian cancer }\end{array}$ & NA \\
\hline & Ankylosing spondylitis - adalimumab, etanercept and infliximab & Yes if severe & No \\
\hline & Head and neck cancer-cetuximab & No & NA \\
\hline & Lung cancer (non-small cell)_-bevacizumab (terminated appraisal) & & \\
\hline & Psoriasis-adalimumab & Yes if severe & No \\
\hline & Coronary artery disease-drug-eluting stents & No except small/long lesions & No \\
\hline & Diabetes-insulin pump therapy & Yes under 12s & Child-adult distinction \\
\hline & Hepatitis B-entecavir & Yes & No \\
\hline & Hepatitis B-telbivudine & No & NA \\
\hline & Macular degeneration (age-related)—ranibizumab and pegaptanib & Yes ranibizumab No pegaptanib & No \\
\hline & Pregnancy (rhesus negative women)-routine anti-D & Yes & No \\
\hline & Venous thromboembolism-dabigatran & Yes & No \\
\hline & Osteoporosis - primary prevention & Yes with restrictions & Yes \\
\hline & Osteoporosis-secondary prevention including strontium ranelate & Yes with restrictions & Yes \\
\hline & Pain (chronic neuropathic or ischaemic)-spinal cord stimulation & Yes-severe & No \\
\hline & Lung cancer (non-small cell)_-erlotinib & Yes & No \\
\hline & Organ preservation (renal) - machine perfusion and static storage & Yes & No \\
\hline & Hyperuricaemia-febuxostat & No-unless allopurinol not possible & NA \\
\hline & Ulcerative colitis (acute exacerbations)—infliximab & Yes-if ciclosporin inappropriate & No \\
\hline
\end{tabular}


disease and drugs for those with short life expectancy were all circumstances in which the standard OALY failed to capture the true value and impact of an intervention. ${ }^{11}$ Ideally weightings would be generated to aid quantification and comparison of different benefits and values attached to OALY in different circumstances. Despite the appeal of such a solution there are profound difficulties in generating a definitive list of 'circumstances' or translating it into quantifiable amounts of weighting per OALY. ${ }^{20}$

\section{ACTUAL NICE DECISIONS AND AGE}

Arguably, the success of the two layers of protection NICE has implemented to avoid ageism is best judged by a review of NICE's track record. Table 2 shows the actual decisions NICE has taken for the years 2008 and 2009. It shows both the decision taken and whether there was any age restriction. It is clear that not all decisions were 'yes' decisions, although they are in the clear majority. However, of the 'yes' decisions, it can be seen that only four had restrictions according to age. These concerned osteoporosis (two decisions), insulin pump therapy for diabetes and neuraminidase inhibitors for influenza. In the neuraminidase case, the discrimination was in favour of the elderly (over 65 years) because of the clear relationship of increasing age with influenza morbidity and mortality risk. In this case, NICE was only ageist in the opposite of the usual sense, and only in a case in which the epidemiology was very clear.

A similar situation arose in the post-menopausal osteoporosis decision. The epidemiology of fracture risk in osteoporosis rises steeply with age after the menopause and the cost-benefits of treating relatively young women (those in their 50s) are much less favourable than the cost-benefits of treating much older women. So there were restrictions in the decision. However, these were rather limited. In the case of secondary prevention, the principal drugs for osteoporosis (the bisphosphonates) were made available to all women over 50 years of age irrespective of cost-benefit, on the grounds that the minority of younger women at risk would have constituted an overzealous restriction. The only other example of age restriction was in the case of insulin pump therapy, when children and adults were treated differentially. The child/adult issue is a sort of age discrimination, but again, one that is not what NICE's antagonists have in mind when making an ageism attack on NICE. It is, however, one that NICE will continue to consider as it explores further the impact and development of its methodology.

\section{CONCLUSION}

This review demonstrates that arguments claiming NICE to be inherently ageist because it uses the OALY are based on a fundamental misunderstanding of the context in which this methodology is applied and the actual calculations it has made. The OALY is one piece of a much more complex set of arrangements that NICE has implemented to ensure its appraisals reflect analysis of an intervention's clinical effectiveness, cost effectiveness, innovation and impact on equity and equality. Through its procedural processes, legal framework and interactions with all potential stakeholders, NICE has implemented robust systems to identify potential for discrimination and developed clear mechanisms to avoid or resolve it. A review of NICE's actual track record provides evidence that these systems have been effective. Implementation of the Equality Act will inevitably present new challenges. The experience NICE has gained and investment it has made in developing a transparent and highly consultative culture puts it in an ideal position to rise to these challenges. It demonstrates that NICE has not been ageist and that it consistently meets its obligation to 'ensure NHS resources are used in a manner that takes both clinical and cost-effectiveness into account; but that also embodies equality'. 21

\section{Competing interests None.}

Patient consent Obtained.

Contributors AS and PL instigated the paper. ND undertook the analysis of relevant legislation and all authors contributed to the writing of the paper. AS is the guarantor

Provenance and peer review Not commissioned; externally peer reviewed.

\section{REFERENCES}

1. Claxton K, Culyer AJ. Wickedness or Folly? The Ethics of NICE's decisions. J Med Ethics 2006:32:373-7.

2. Harris J. It's not NICE to discriminate. J Med Ethics 2005;31:373-5.

3. Harris J. Nice and not so nice. J Med Ethics 2005:31:685.

4. Edlin R, Round J, McCabe C, et al. Cost-effectiveness Analysis and Ageism: A Review of the Theoretical Literature. A Report for the Department of Health. Leeds: University of Leeds, 2008.

5. National Institute for Health and Clinical Excellence. Developing NICE multiple technology appraisals (MTAs). 2010. http://www.nice.org.uk/aboutnice/howwework/ devnicetech/developing nice multiple technology appraisals.jsp?domedia $=1$ \&

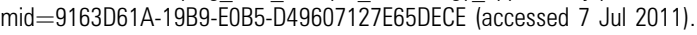

6. Gold M, Siegel J, Russel L, et al. Cost-effectiveness Analysis in Health and Medicine. New York: Oxford University Press, 1996.

7. The University of York, Centre for health Economics. Team for Economic Evaluation and Health Technology Assessment. http://www.york.ac.uk/che/research/ teams/teehta/projects/methodological-research/ (accessed 7 Jul 2011).

8. Paulden M, Culyer AJ. Does Cost-effectiveness Analysis Discriminate Against Patients with Short Life Expectancy? Matters of Logic and Matters of Context. CHE Research Paper 55. York: Centre for Health Economics, University of York, 2010.

9. National Institute for Health and Clinical Excellence. Guide to the Methods of Technology Appraisal. London: NICE, 2008.

10. National Institute for Health and Clinical Excellence. Social Value Judgements Principles for the Development of NICE Guidance. 2nd edn. 2008. http://www.nice. org.uk/media/C18/30/SVJ2PUBLICATION2008.pdf (accessed 7 Jul 2011).

11. National Institute for Health and Clinical Excellence. Report on NICE Citizens Council Meeting: Inequalities in Health. 2006. http://www.nice.org.uk/niceMedia/pdf/ CCreportonHealthlnequalities.pdf (accessed 7 Jul 2011).

12. National Institute for Health and Clinical Excellence. NICE Citizen's Council Report on Age. 2004. http://www.nice.org.uk/getinvolved/ patientsandpublicinvolvement/opportunitiestogetinvolved/citizenscouncil/reports/ nice citizens council report on age.jsp (accessed 7 Jul 2011).

13. National Institute for Health and Clinical Excellence. NICE Equality Scheme and Action Plan 2007-2010. http://www.nice.org.uk/aboutnice/howwework/ niceequalityscheme.jsp?domedia $=1 \mathrm{gmid}=$ FBCF7611-19B9-EOB5 D44D7B40FEE918DA (accessed 7 Jul 2011)

14. National Institute for Health and Clinical Excellence. NICE's revised Equality Scheme 2010-2013. http://www.nice.org.uk/aboutnice/howwework/ niceequalityscheme.jsp?domedia=18mid=9531E7FC-19B9-E0B5-D4A3CC036ABED5AE (accessed 28 Dec 2011).

15. Carruthers I, Ormondroyd J. Age equality in health and social care. 2009. http:// www.dh.gov.uk/prod consum dh/groups/dh digitalassets/documents/digitalasset/ dh 107398.pdf (accessed 7 Jul 2011).

16. National Institute for Health and Clinical Excellence. NICE Annual Equality Report 2010. http://www.nice.org.uk/media/F13/6F/ BoardMeetingSept10AnnualEqualityReport.pdf (accessed 7 Jul 2011).

17. National Institute for Health and Clinical Excellence. NICE Citizen's Council Report on Departing from the Threshold. http://www.nice.org.uk/media/231/CB/ NICECitizensCouncilDepartingThresholdFinal.pdf (accessed 7 Jul 2011).

18. National Institute for Health and Clinical Excellence. Supplementary Advice to the Appraisals Committees 2009. http://www.nice.org.uk/media/E4A/79/ SupplementaryAdviceTACEoL.pdf (accessed 7 Jul 2011).

19. National Institute for Health and Clinical Excellence. End of life treatments: summary response to consultation. 2009. http://www.nice.org.uk/media/97C/9D/ EoLConsultationSummaryResponses.pdf (accessed 7 Jul 2011).

20. National Institute for Health and Clinical Excellence. The Social Value of a OALY. http://www.nice.org.uk/aboutnice/howwework/researchanddevelopment/ SocialValueOfAQALY.jsp (accessed 7 Jul 2011).

21. Rawlins M, Dillon A. "NICE discrimination". J Med Ethics 2005;31:683-4. 